\title{
Efficacy of ultrasonography in lymphatic malformations: diagnosis, treatment and follow-up: a case report.
}

\author{
Ahmet Aslan', Ramazan Büyükkaya ${ }^{2}, \operatorname{Sinan}_{\operatorname{Tan}^{1}, \text { Cüneyt Erdoğan}}^{3}$, Bahattin Hakyemez ${ }^{3}$
}

${ }^{1}$ Department of Radiology, Şevket Yılmaz Research and Education Hospital, ${ }^{2}$ Department of Radiology, Düzce University Medical Faculty, ${ }^{3}$ Department of Radiology, Uludag University Medical Faculty, Turkey

\begin{abstract}
Lymphatic malformation (LM) is a localized and rare benign anomaly of the lymphatic system. Surgery is the primary form of treatment, but total resection is difficult and generally not possible. The least invasive and most effective form of treatment is injection sclerotherapy with sclerosing agents. Here, we report a case of LM in a baby, detected at prenatal ultrasound. The aim of this report is to assess the importance of ultrasonography in the prenatal diagnosis, therapy and follow-up of LM's.

Keywords: cystic lymphangioma, prenatal ultrasonic diagnoses, sclerotherapy.
\end{abstract}

\section{Introduction}

Lymphatic malformations (LM) are relatively rare benign lesions, which form due to abnormal development and proliferation of the lymphatic system [1]. They are benign lesions and contain tissue fluid. Surgery is the primary mode of therapy. But because LM's extend around major neurovascular structures, removal is generally incomplete and recurrence is high [2]. The least invasive, most effective form of treatment is injection sclerotherapy. Here, we report a case of LM in a fetus detected at prenatal ultrasonography and treated with OK-432 injection sclerotherapy in the first month of life. Our case report demonstrates the importance of ultrasonography in the prenatal diagnosis, therapy and follow-up of LM's.

\section{Case report}

A 22 year-old, gravida 2, para 1 woman visited our hospital for ultrasonographic evaluation at an estimated gestational age of 34 weeks. At prenatal ultrasonogra-

Received 01.04.2013 Accepted 15.05.2013

Med Ultrason

2013, Vol. 15, No 3, 244-246

Corresponding author: Ahmet Aslan, MD.

Şevket Yılmaz Education and Research Hospital Radiology Department

16260, Yildırım, Bursa, Turkey.

Tel.: +905326063663

E-mail: aslahmet@gmail.com phy we detected a $70 \times 30 \times 55 \mathrm{~mm}$ macrocystic mass in the right frontal region that reached the right orbita and auricula and minimally displaced the right eye inferiorly and medially. The lesion was outside the cranium and had no relation to the neural parenchyma (fig 1a). There was no detectable flow at Doppler ultrasonography in cystic spaces. On fetal magnetic resonance imaging (MRI), the lesion had a macrocystic appearance and the neurocranium was intact (fig 1b). Both sonography and fetal MRI did not detect any further anomaly. Due to its appearance, location and ultrasonographic findings, the lesion was accepted as a macrocystic type LM. The importance of the diagnosis of LM's at prenatal ultrasonography resides in determining the type of LM, choosing the method of delivery, whether by cesarean section or vaginally, and early treatment, before it is complicated by infection or hemorrhage. We scheduled the patient for injection sclerotherapy with OK-432 after birth. The mother delivered a healthy boy by caesearean section at 39 weeks of gestation (fig 1c).

At one month of age, under sedation anesthesia and ultrasonographic guidance, the cyst was punctured with an 18-gauge needle, fluid was aspirated and OK-432 (concentration $0.1 \mathrm{mg} / 10 \mathrm{~mL}$ ) was injected. A total amount of 0.2 $\mathrm{mg}$ of OK-432 was used in one session. The patient was observed for 24 hours for low grade fever $\left(38-39^{\circ} \mathrm{C}\right)$ and acute local or systemic allergic reactions in the hospital. No acute allergic reaction or fever was seen. After 2 days the 


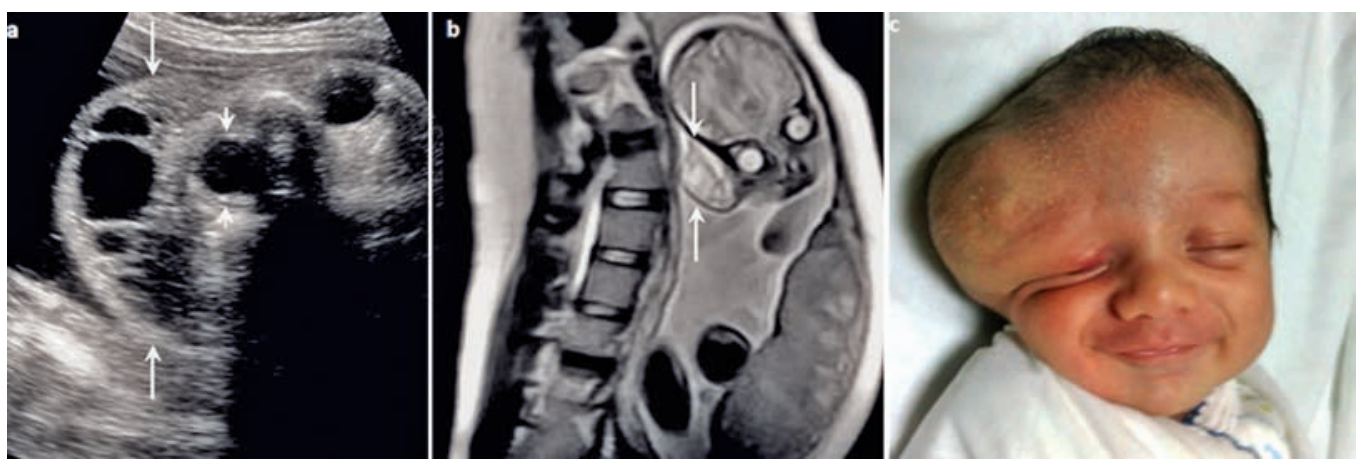

Fig 1. Lymphatic malformation in a 34 week gestational age fetus. a. In prenatal ultrasonography a predominantly macrocystic, thick septated lesion in the right frontal region (long arrows) is observed. Lesion is outside the neurocranium and there is no relationship between the orbital cavity and the cyst (small arrows). $b$. Sagittal T2 weighted MRI seguence showing the lymphatic malformation (arrows). The MRI did not detect any further anomaly than the sonography. c. Frontal view of the baby after the first month of life.

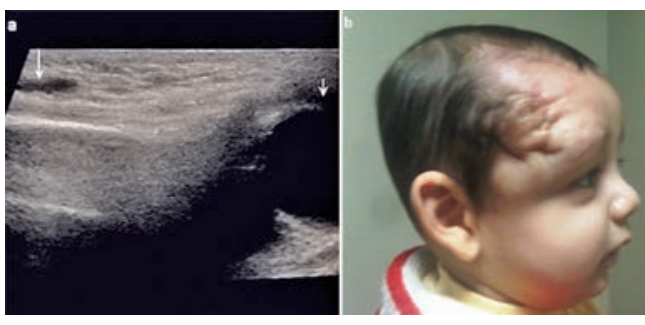

Fig 2. At 6 months after sclerotherapy. a. Frontal view of the baby after the procedure shows a significantly regressed lesion. $\mathrm{b}$. In the B mode sonography image, there is a small cystic space (long arrow) and hyperechoic areas representing sclerosis after almost complete resolution of the malformation. The small arrow indicates the right orbital cavity.

patient demonstrated erythema and swelling of the lesion. After 1 week symptoms regressed without medication. At the 6th month clinical follow-up, the volume of the lesion was reduced to approximately $20 \%$ of its initial state and no complications of the mass were observed (fig 2a). In ultrasonography, macrocystic spaces were filled with echogenic fluid, which represented the sclerosis (fig 2b). The response to treatment was assessed as a marked response.

\section{Discussions}

Prenatal ultrasonographic applications have increased detection of congenital vascular anomalies. LM's are abnormally developed lymphatic channels and cysts. LM's can be found at any age of life, but they usually occur before two years of age and most commonly arise in the head and neck region [3]. The precise etiology of LM's have not been defined yet. There may be congenital mal- formations of lymphatic vessels or some factors affecting lymphatic drainage [3]. LM's contain tissue fluid and can be macrocystic, microcystic or mixed in structure [4]. Surgery is the primary form of treatment for LM's. But total resection is difficult and generally not possible because the boundaries cannot be determined exactly and they have a close relationship to vital structures. This increases recurrence and morbidity $[2,5]$. Other alternative methods are aspiration, radiofrequency ablation/diathermy, laser therapy, and injection sclerotherapy [6,7]. The least invasive, most effective form of treatment is injection sclerotherapy. It is especially effective for the macrocystic type and for superficially located lesions. Dextrose, doxycycline, bleomycin and OK-432 (picibanil) can be used for injection sclerotherapy. The most commonly accepted sclerosing agents are bleomycin and OK-432 [4]. OK-432 is a lyophilized biological product containing a mixture of the low virulence Su strain of group A Streptococcus pyogenes inactivated with Penicillin-G $[8,9]$.

Radiologic evaluations help to identify the extension of the lesion and can be best demonstrated by magnetic resonance imaging and computed tomography. As in our case, however, ultrasonography was very useful for evaluating extension and relationship to adjacent structures of LM's. Also, detecting the LM by ultrasonography changed the way of delivery. Ultrasonography is an accurate technique for both prenatal detection and characterization of these lesions. During injection sclerotherapy real-time ultrasonography provided guidance for multiple planes and angled approaches, and was useful for assessing the response to therapy at follow-up. Thus, ultrasonography is a readily available, easy to use, noninvasive and low-cost imaging modality in the diagnosis, injection sclerotheraphy and follow-up of LM's. 


\section{References}

1. Gilony D, Schwartz M, Shpitzer T, Feinmesser R, Kornreich L, Raveh E. Treatment of lymphatic malformations: a more conservative approach. J Pediatr Surg 2012; 47: 1837 1842.

2. Bloom D, Perkins JA, Manning SC. Management of lymphatic malformations. Curr Opin Otolaryngol Head Neck Surg 2004; 12: 500-504.

3. Zhou Q, Zheng JW, Mai HM, et al. Treatment guidelines of lymphatic malformations of the head and neck. Oral Oncol 2011; 47: 1105-1109.

4. Sherer DM, Perenyi AR, Glick SA, et al. Prenatal sonographic findings of extensive low-flow mixed lymphatic and venous malformations. J Ultrasound Med 2006; 25: 1469-1473.
5. Marler JJ, Fishman SJ, Upton J, et al. Prenatal diagnosis of vascular anomalies. J Pediatr Surg 2002; 37: 318-326.

6. Smith MC, Zimmermann MB, Burke DK, Bauman NM, Sato Y, Smith RJ; OK-432 Colloborative Study Group. Efficacy and safety of OK-432 immunotherapy of lymphatic malformations. Laryngoscope 2009; 119: 107-115.

7. Song JN, Jung SL, Lee SH, Park SN. A case of large auricular lymphangioma. Int J Pediatr Otorhinolaryngol Extra 2012; 7: 100-102.

8. Şanlıalp I, Karnak I, Tanyel FC, Şenocak ME, Büyükpamukçu N. Sclerotherapy for lymphangioma in children. Int J Pediatr Otorhinolaryngol 2003; 67: 795-800.

9. Rautio R, Keski-Nisula L, Laranne J, Laasonen E. Treatment of lymphangiomas with OK-432 (Picibanil). Cardiovasc Intervent Radiol 2003; 26: 31-36. 